Portland State University

PDXScholar

1989

\title{
Some visual issues of painting : an exploration of the painting process
}

Barbara Leedy Branham

Portland State University

Follow this and additional works at: https://pdxscholar.library.pdx.edu/open_access_etds

Part of the Art Practice Commons, and the Painting Commons Let us know how access to this document benefits you.

\section{Recommended Citation}

Branham, Barbara Leedy, "Some visual issues of painting : an exploration of the painting process" (1989). Dissertations and Theses. Paper 3856.

https://doi.org/10.15760/etd.5740

This Thesis is brought to you for free and open access. It has been accepted for inclusion in Dissertations and Theses by an authorized administrator of PDXScholar. Please contact us if we can make this document more accessible: pdxscholar@pdx.edu. 
SOME VISUAL ISSUES OF PAINTING:

AN EXPLORATION OF THE PAINTING PROCESS

by

BARBARA LEEDY BRANHAM

A thesis submitted in partial fulfillment of the requirements for the degree of

MASTER OF FINE ARTS

in

ART : PAINTING

Portland State University
1989 
TO THE OFFICE OF GRADUATE STUDIES:

The members of the committee approve the thesis of Barbara Leedy Branham presented October 19, 1989.

Byron J. Garbner, Chair
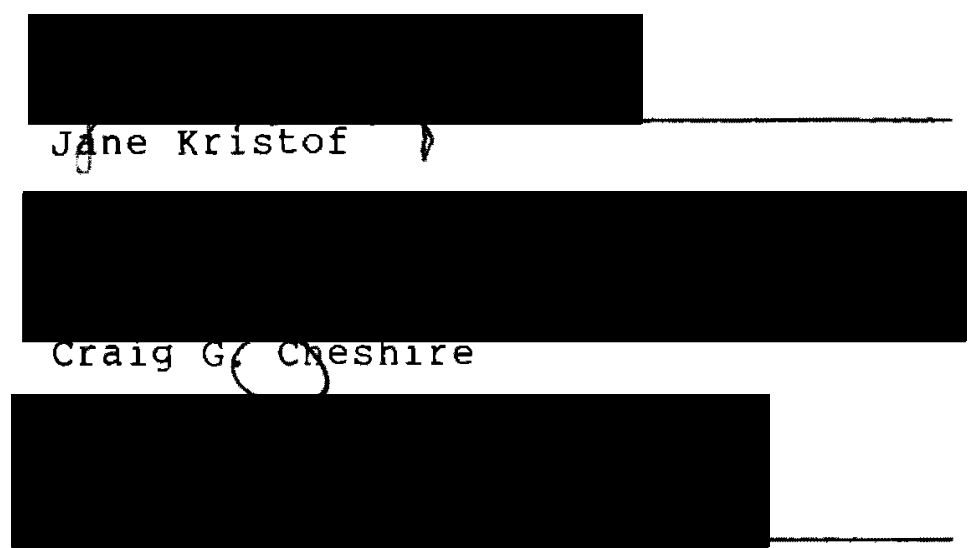

James S. Hibbard

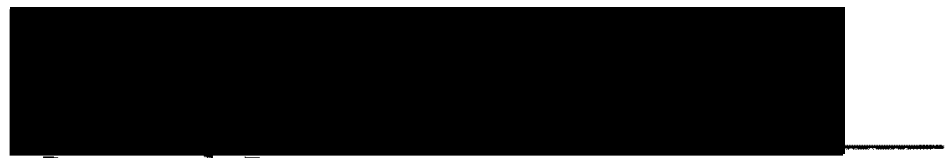

Bernard Ross

APPROVED :

L. Robert Kasal, Chair, Art Department

C. William Savery, anterim vice provost for

Graduate Studies and Research 
TABLE OF CONTENTS

PAGE

LIST OF FIGURES.................... iv

INTRODUCTION. . . . . . . . . . . . .

The First Year...................... 2

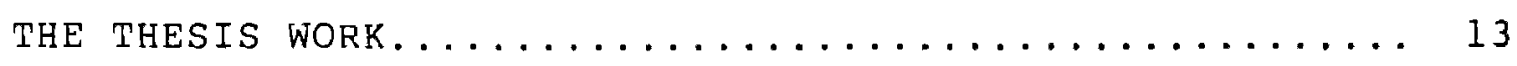

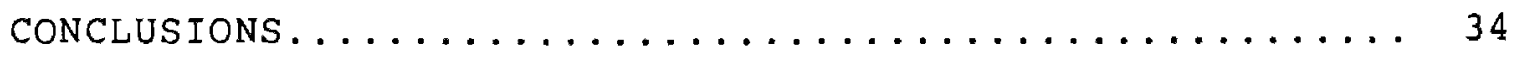

REFERENCES CITED.................... 36 


\section{LIST OF FIGURES}

1. Portrait of Hugo \#1................. 4

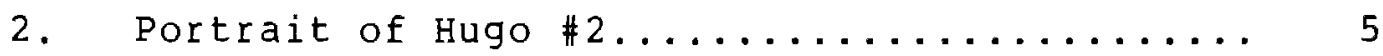

3. Stil1 life: art supplies............... 7

4. Green study.......................... 9

5. $\operatorname{Red} s t u d y \ldots \ldots \ldots \ldots \ldots \ldots$

6. Black study.......................... 11

7. Industrial molds $\# 1 \ldots \ldots \ldots \ldots \ldots \ldots$

8. Still life and table................ 17

9. cycle............................ 20

10. Two views........................ 22

11. Table and shadow.................... 24

12. The necromancer's studio............... 26

13. $\operatorname{Triptych\ldots \ldots \ldots \ldots \ldots \ldots \ldots \ldots \ldots \ldots \ldots \ldots .\ldots \ldots } 28$

14. Tables and skull................... 30

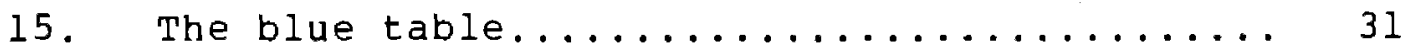




\section{INTRODUCTION}

You can enliven a construct of paint by doing any number of manipulations and additions to what one sees. This makes it possible for representational painting to be both abstract and real simultaneously.

Wayne Thiebaud (Tsujimoto 1985, pp. 39, 40)

When I entered the graduate program in painting $I$ felt that my background and experience had prepared me to handle the materials an artist uses but had not prepared me for the kind of introspection and visual analysis necessary to become a good painter. Commercial art, which was the focus of my undergraduate work, demanded that the client's interest be uppermost in creating the idea. At a later time, I completed work for the Master of Arts in Teaching but this did not contribute substantially to developing a means to self-knowledge. The paintings produced during this period and subsequent years were adequate, but they were not the results of an intense exploration into my own artistic personality or of a sustained inquiry into the nature of the painting process.

When a move across the country made returning to graduate school a possibility I enrolled for a year of post-baccalaureate work. I wanted to produce a body of more recent work for submission when I applied to the graduate program. During this year I found myself 
returning to representational art. Considering my early training this seemed a natural choice and I found genuine pleasure in reviving and honing the skills of observational painting. However, once the first flush of excitement over being able to create successful illusions on the canvas waned I became increasingly frustrated by my inability to move past merely rendering subject matter. I wished to take bigger risks in my work but I was having trouble finding the means to do so. Simply jumping into greater abstraction seemed too arbitrary a step. I had produced abstract painting for years but I did not feel I had the intellectual foundation to continue to feel any conviction in my work. I did not want to fall into that trap again. It was necessary to work through the problem step by step.

THE FIRST YEAR

During the first quarter of the graduate program I tried working with figurative compositions. In an effort to get away from dependency on direct observation I based these works on drawings and on imagination. The results, however, were forced and artificial. The paintings lacked an authentic quality and a straight forward honesty that I felt were conveyed in work that was based on observation. Furthermore, a concern with subject matter and story telling was interfering with my ability to concentrate on the formal elements in the paintings. searching for a 
remedy I decided to return to direct observation.

A friend agreed to pose which allowed a change from life class poses to a more informal atmosphere. The resulting paintings (Figures 1 and 2 ) were more satisfying than previous work; however, working from a model presented a new set of problems. Aside from the difficulty of finding people to model, there was the hurdle of overcoming the psychological barrier that made it difficult for me to concentrate on formal concerns while painting the figure. Finally, I had to face the fact that I was having difficulty concentrating on these issues because of a stubborn concern with getting a likeness.

It was a source of considerable concern that by the beginning of spring quarter I still had not found a clear direction. Nevertheless, I had eliminated some approaches that did not work well for me. One day I noticed a disorderly pile of art supplies on a table by the wall in my studio and I thought it might offer possibilities as subject matter. In earlier still life paintings I had placed objects to appear casually or accidentally arranged but there always seemed to me to be a strong sense of premeditation and, therefore, a troubling predictability in the still life groupings. This jumbled pile on the table was genuinely unplanned and the objects were commonplace, unlike the objects usually chosen for still life compositions because they have sentimental associations or 


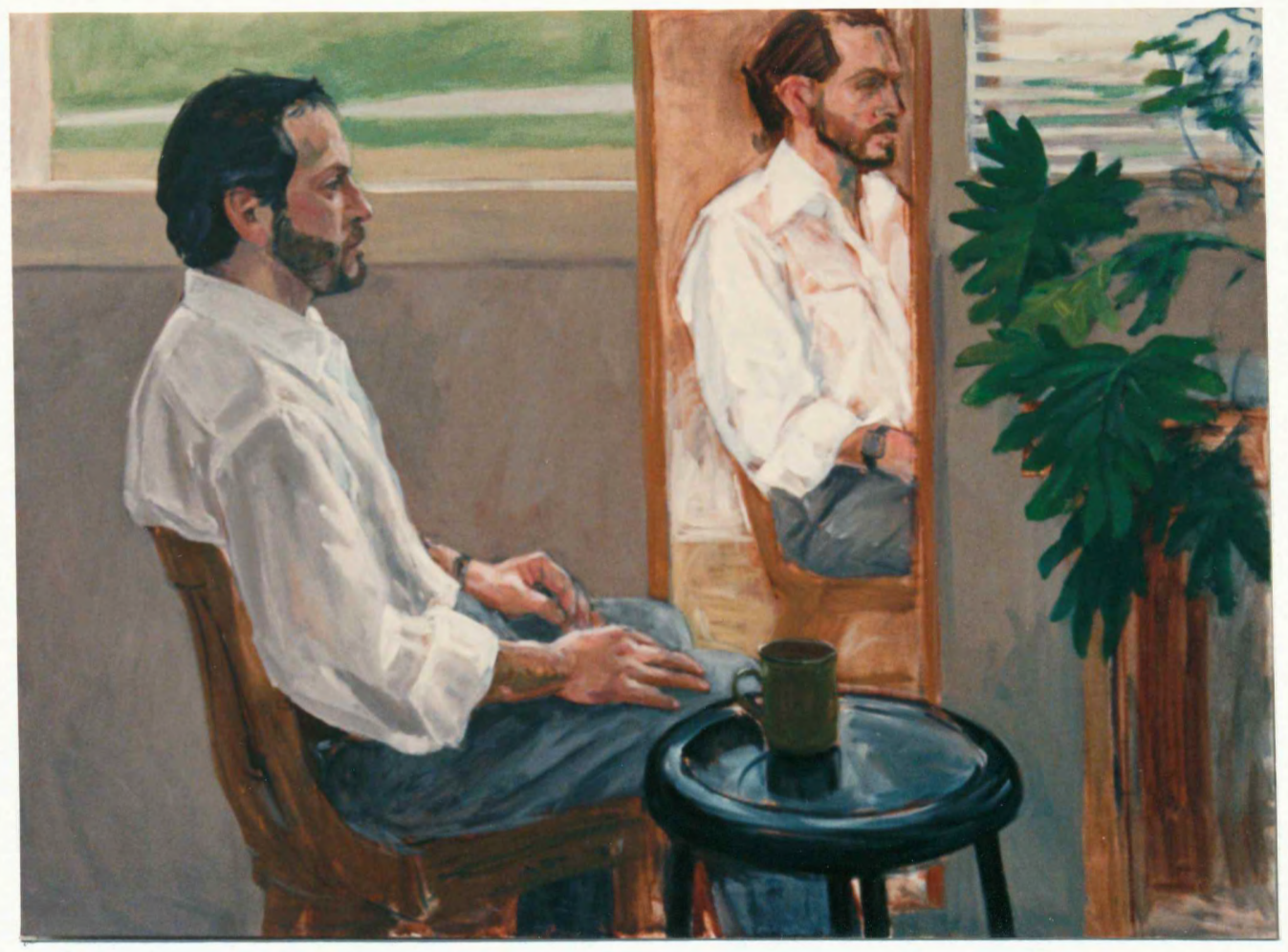

Figure 1. Portrait of Hugo \#1 


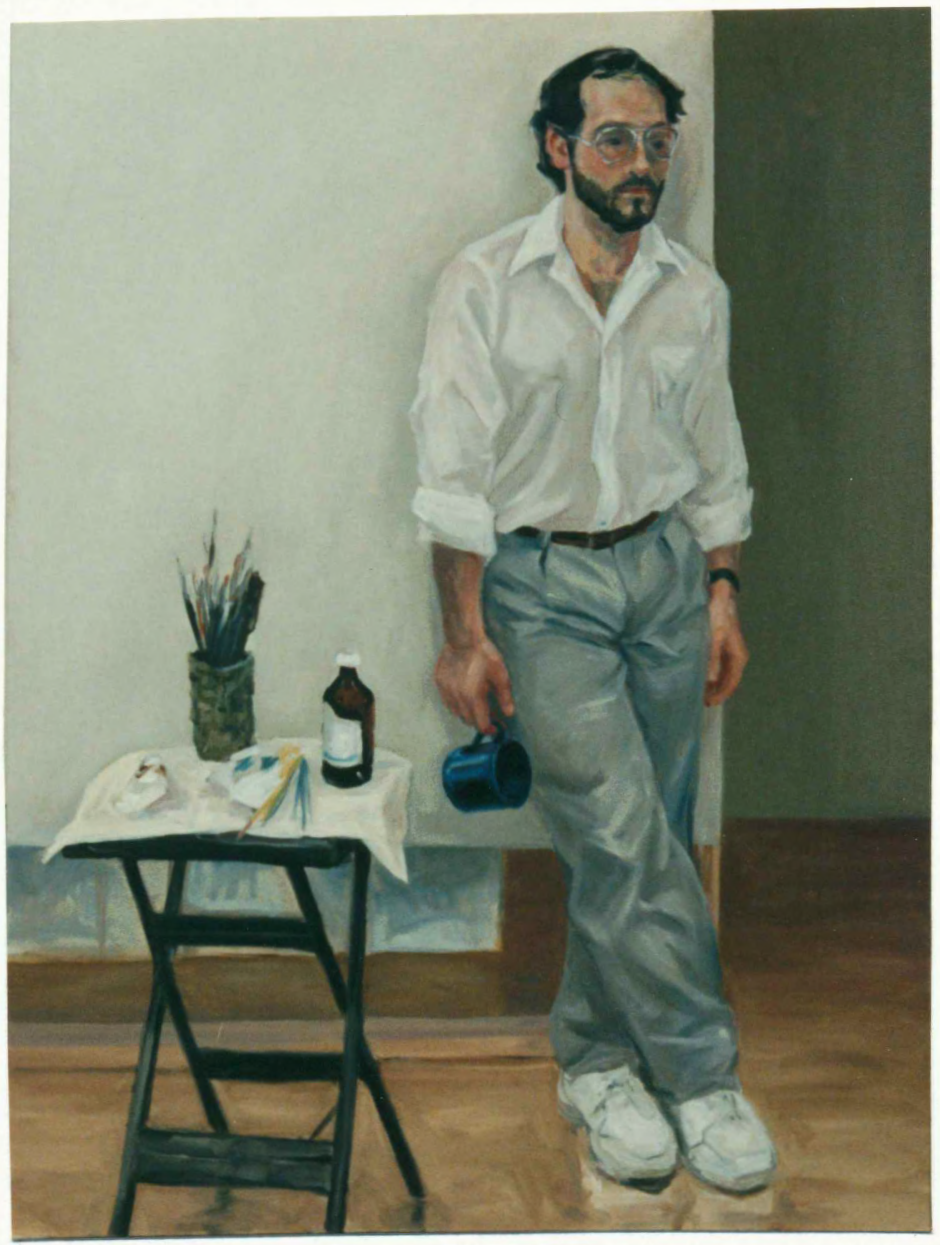

Figure 2. Portrait of Hugo \#2 
are attractive. This new collection of objects would seldom elicit a second glance from anyone and that was precisely why they suited my purposes. There was no hierarchy of psychological importance to deal with, no pressure to get a likeness. The subject matter was too ordinary to be psychologically inhibiting. Now I felt free to take the liberties with form and color I had been reluctant to take when working with the more "important," psychologically charged subject matter of the human figure. Details that might be distracting to the total effect were eliminated and divisions between objects were blurred to create more ease of visual movement within groups of objects. In the completed painting (Figure 3 ) the brushwork is looser and less fussy than in previous paintings. This was a break through painting. I felt I was beginning to understand in a way I had not before that painting was not about subject matter. The idea that the formal elements could be manipulated to create a more powerful re-statement of observed objects was becoming clearer to me.

At this point I decided to concentrate on specific visual issues. Color became the first area that I wanted to explore because this seemed like a promising route to breaking new ground. I set myself the problem of finding a way to remain within the bounds of local color and yet explore new hue ranges so that, in terms of color at least, 


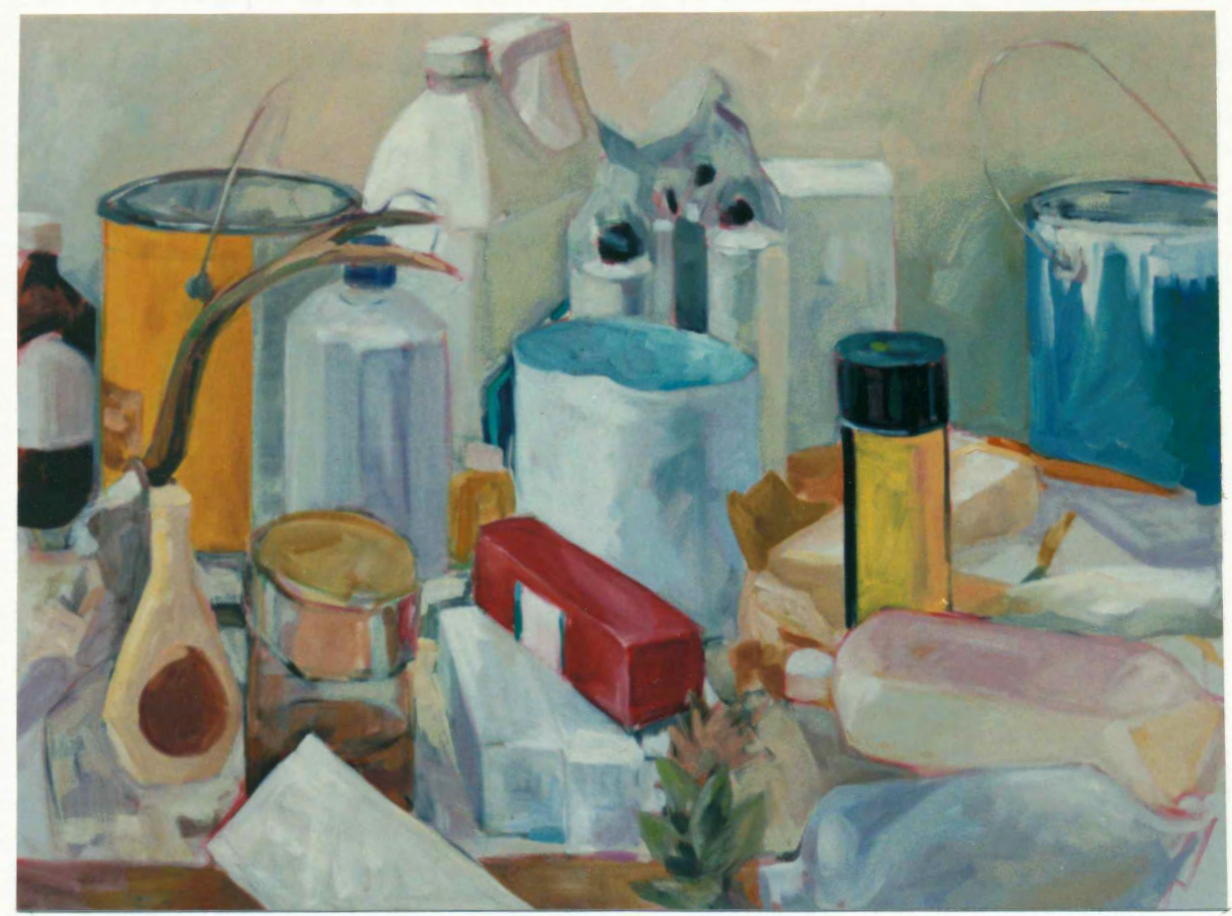

Figure 3 . Still life: art supplies 
the painting was not merely a copy of what was in front of me. It was not my inclination to use purely arbitrary color at this point in my work.

I began a series of pastels, working them over a watercolor wash which was brushed on the paper to establish a ground color. The pastels were an ideal medium for exploration. They allowed me more freedom in experimenting with color because I could do a pastel painting much more quickly and spontaneously than an oil painting. It was possible to try numerous colors and quickly discard unsuitable choices and it was easy to remove or re-work passages since there was no need to wait for the pastels to dry. I was willing to try more daring color experiments since each piece represented a time commitment of hours rather than days or weeks.

By using a ground color, unrelated to the local colors of the still life objects, I was forced to make careful color choices to maintain a hue range that would be consistent, rather than arbitrary. The ground hue forced me to abandon habitual color choices. Comparing a series of these works, with different ground colors for each, it was surprising to see how much difference in the hue range there was from one to the next (Figures 4, 5, 6). Each one was consistent in acknowledging local color, yet the colors used differed radically in each drawing. The ground color intensified the colors in its complementary range and 


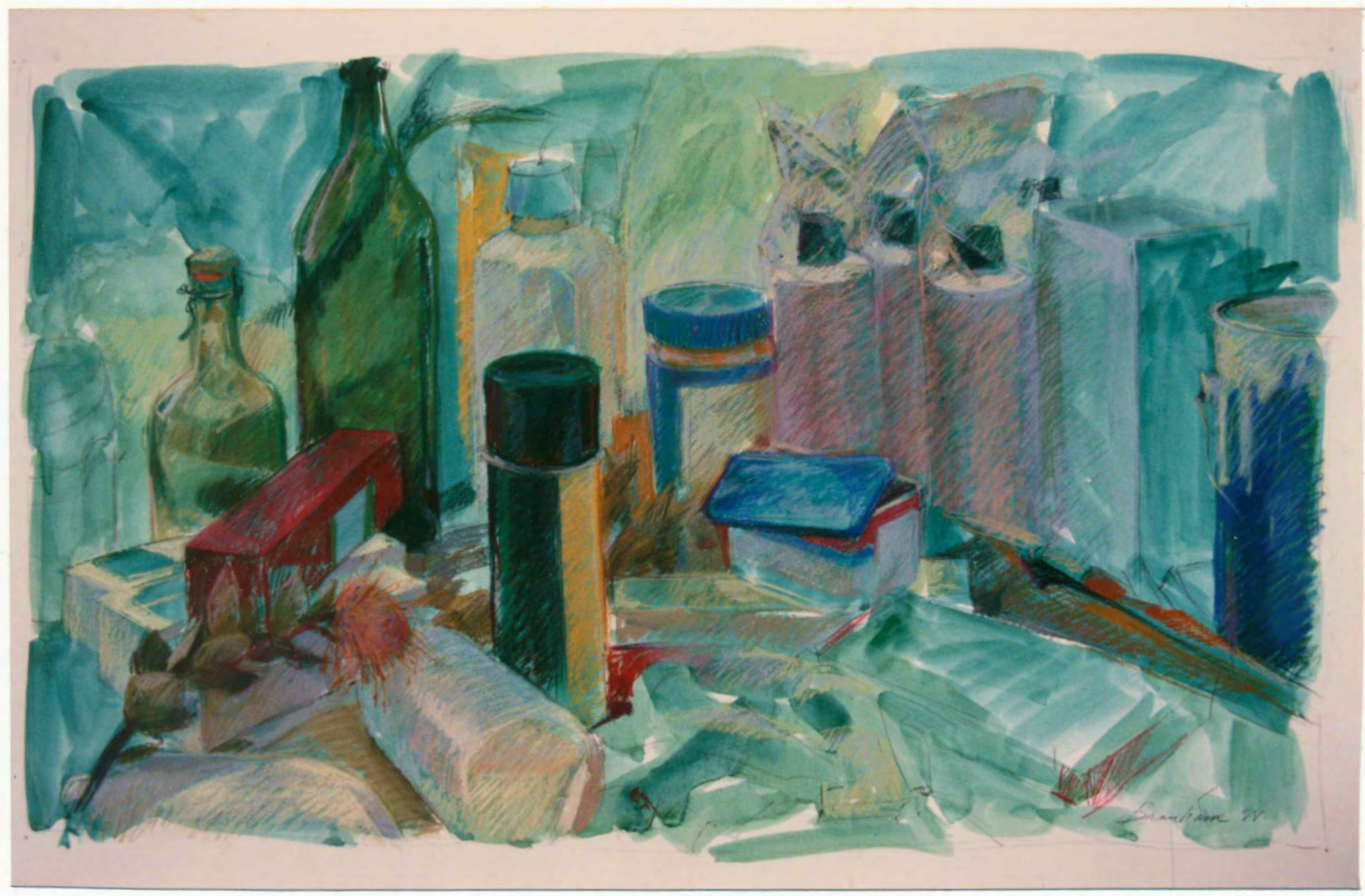

Figure 4. Green study 


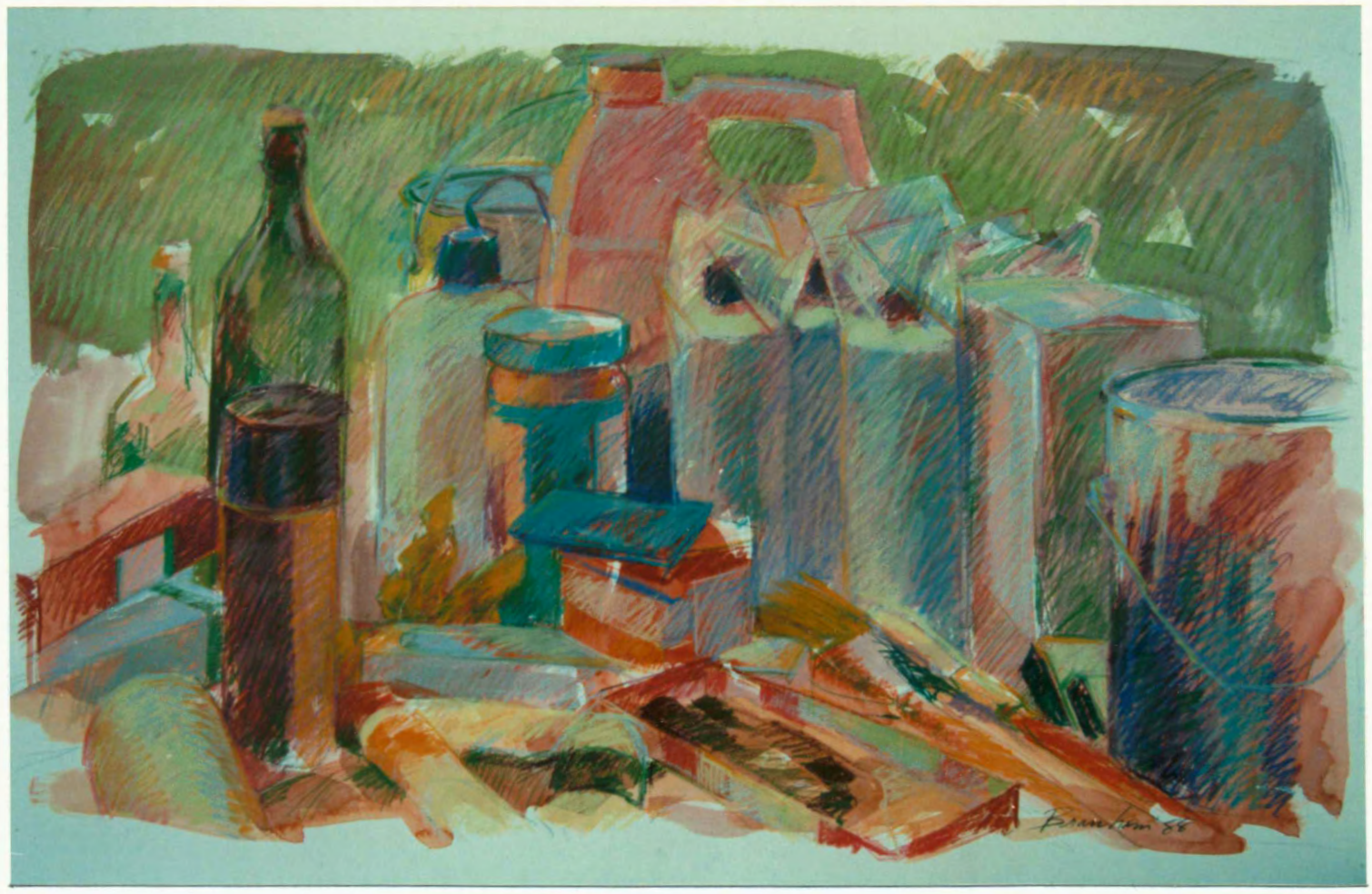

Figure 5. Red study 


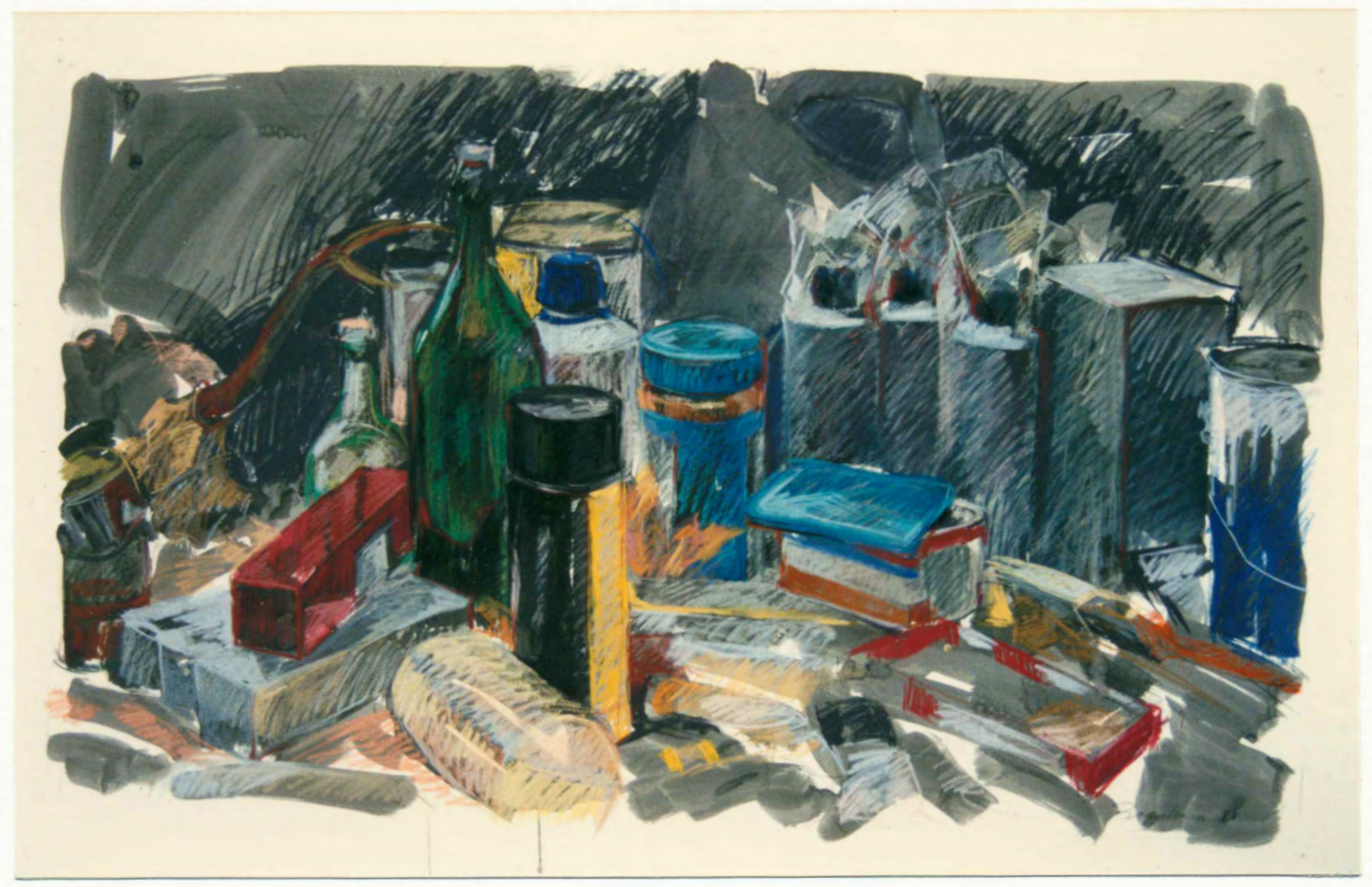

Figure 6 . Black study 
dulled analogous hues so that constant adjustments in hue, value and intensity had to be made to counter these effects and achieve color integration. Additionally, the ground hue permeated every aspect of the composition, unifying it and, at the same time, forcing the colors of the objects into an unanticipated hue range. 
THE THESIS WORK

When the time came to formulate a thesis proposal I felt that I had eliminated the concepts and working methods that did not suit me temperamentally. I had concluded that working from observation was necessary to produce convincing work. Additionally, working from a casual or chance arrangement of objects that had no sentimental attachments, helped me to concentrate on visual issues and allow for accidental or spontaneous developments in the work. I wanted to continue working from still life arrangements since they were easily set up in the studio and would be available for as long as needed.

During the summer I worked on a series of pastels using foundry forms as subject matter. Since these molds were not familiar or easily identifiable objects my initial reaction was to treat them in a representational manner. Experience had shown that abstraction requires objects familiar to the viewer so they will be identifiable in spite of distortion and reduction. The first drawings were fairly straight forward but as I continued to work I tried to pay more attention to the underlying abstract structure of the composition. I began to let the wash that made up the ground color play a greater role in the drawing. For example, in Industrial molds \#l (Figure 7) I allowed the 


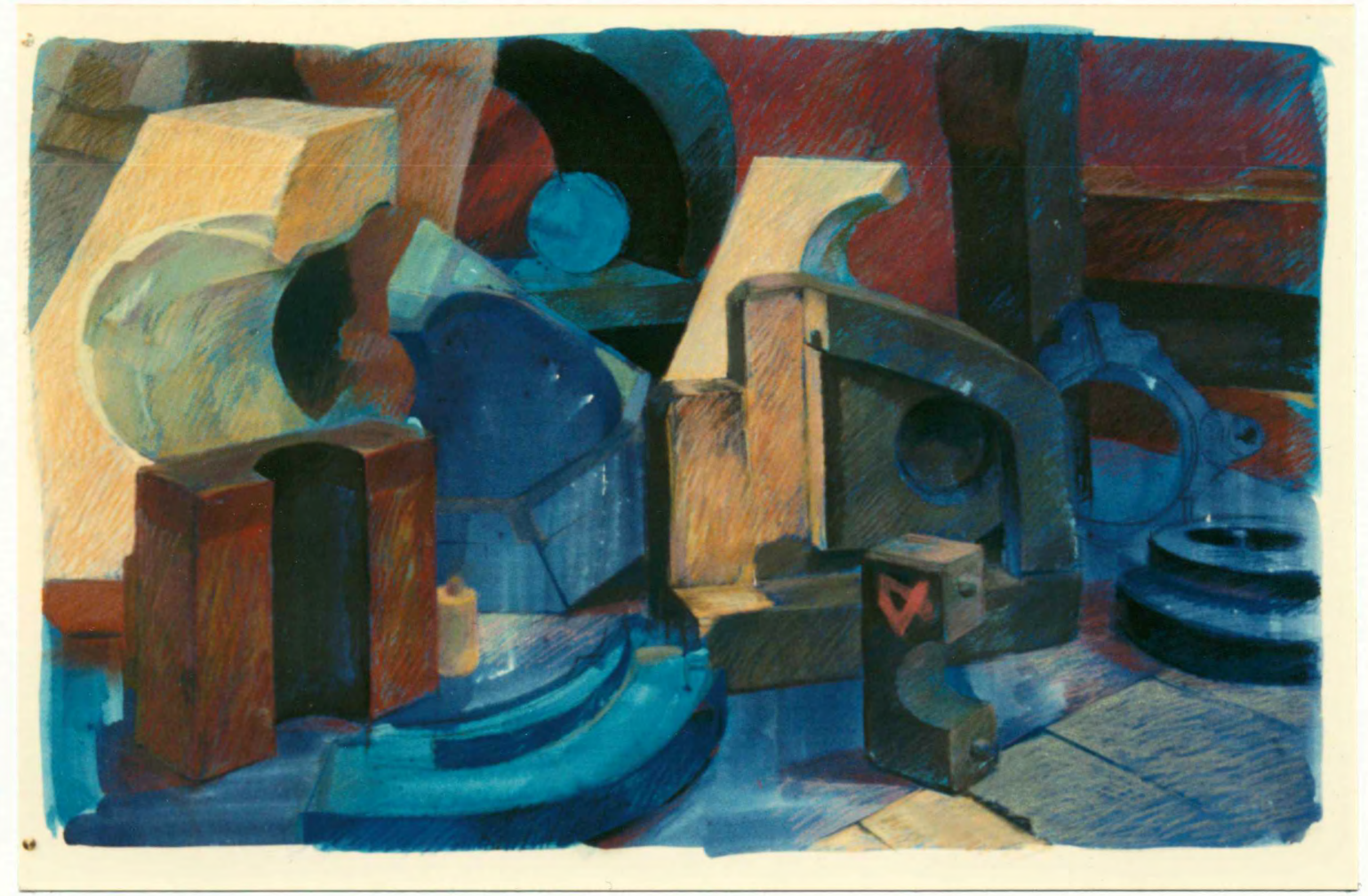

Figure 7. Industrial molds \# 1 
blue ground color to show through in several areas. This device helped unify the composition and create a strong atmospheric quality. Also, these areas, which are in a less finished state, serve to remind the viewer that drawing is a process and an interpretation of observed reality rather than merely a clever illusion.

During the fall quarter I concentrated on composition, referring to paintings by Manet and Degas for inspiration. These artists achieved the impression of casual glimpses of the world by means of off center balance and dramatic cropping, compositional ideas that seemed particularly useful for my purposes. At the same time I was becoming increasingly interested in the idea of flattening the form, of reaffirming the picture surface. Cezanne, in particular, was an inspiration at this point. His use of a tilted ground plane and breaks in the edges of color areas which allow the eye to move easily from one plane to another, even spatially widely separated planes, were ideas I began to try to incorporate in my paintings.

I began what became a series of paintings based on the industrial molds. The composition of the first painting has the foundry forms on a table in the corner of my studio. This arrangement was dictated by the realization that the industrial molds, while interesting forms, were unknown to most people. Therefore, they needed to be placed in a familiar context if I was going to be able to 
treat them in any other way than representationally. I realized this after I had started a painting in which the entire composition was a near view of the pattern molds. It soon became obvious that the composition would be very abstract, consisting solely of large interlocking geometric shapes. This offered no opportunity to pursue the idea of creating tension between spatial illusion and the two dimensional surface since the composition made it difficult to tell which was which. I realized that I needed to place the objects in a larger, more spatially varied environment. This first painting was a fairly straight forward rendering but I wanted to use the idea of the casual point of view. Therefore, the table and its still life is pushed to the right side of the composition and cropped at the edge. Some details in both the foreground and the background are suppressed to create larger units of shape. I also experimented in a mild way with the use of color breaks between planes. Aspects of this painting suggested a move to a more dramatic simplification in the next painting (Figure 8 ). The objects on the table are treated as a large, dark mass with vague suggestions of individual details. I also began to suggest tranparency in the objects as a further means of linking them visually. The floor plane is tilted more than the table top which creates a subtle tension between the conflicting perspectives. I deliberately placed the feet of the table legs on the 


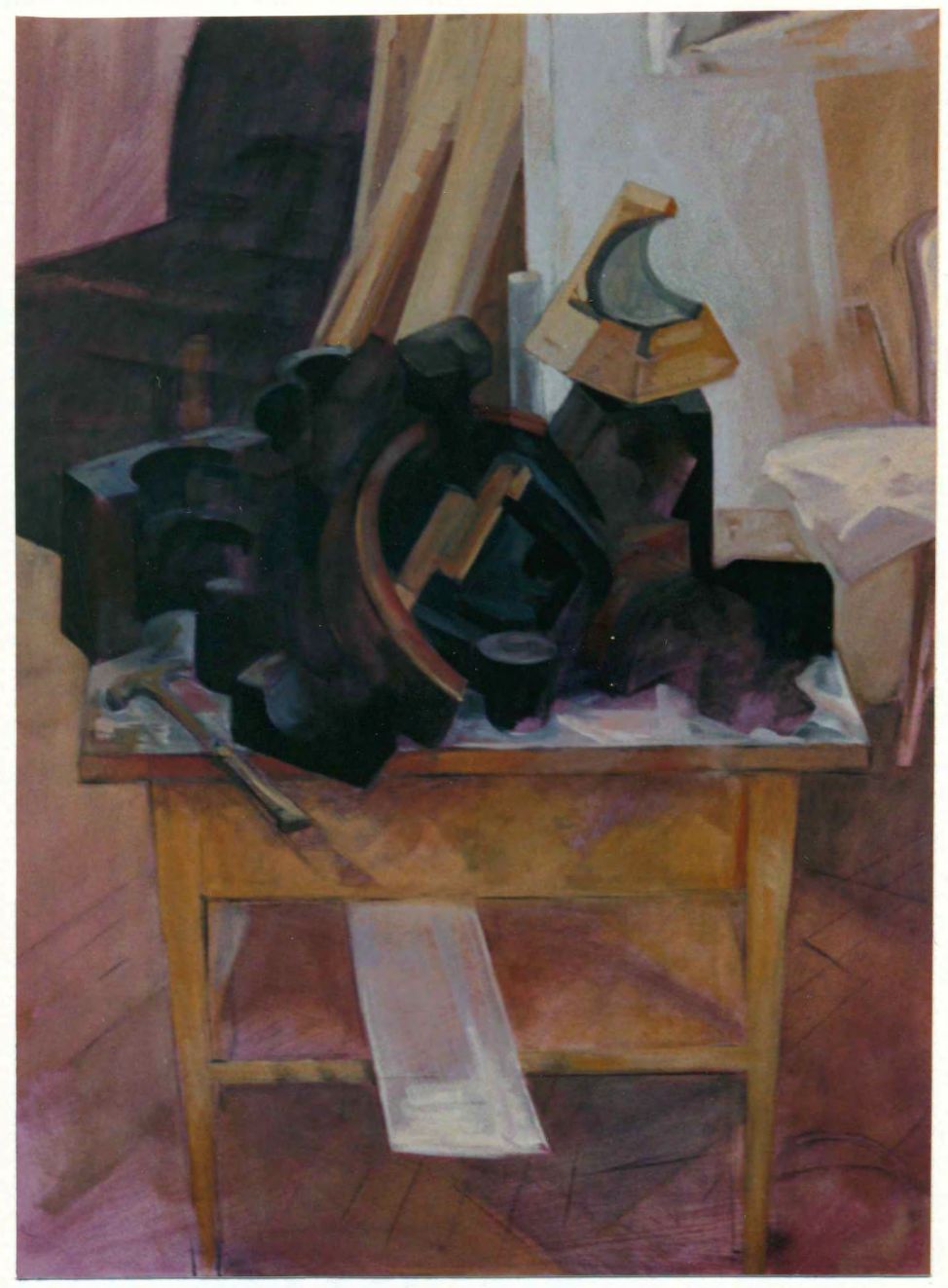

Figure 8. Still life and table 
bottom edge of the canvas to flatten the image and then countered this with the suggestion of perspective in the shape of the table. In this painting I moved a small step away from strictly local color: the painting is based on a yellow-violet combination. The use of washes with passages of more thickly applied paint was also implemented to give greater variety to the surface. I was becoming more and more interested in the dissonant effect of playing a painterly surface against the illusion of depth. Charcoal lines were left on the surface as a further means of nullifying spacial illusion because of the abstract quality of 1 ine.

My interest in Cezanne's methods naturally led to an interest in cubism. The use of multiple views of an object as an alternative to Renaissance perspective suddenly seemed to be a very appealing possibility for my work. However, I was not interested in the complex fracturing of the form seen in analytic cubism. I used the idea of overlapping views obtained from minor shifts of viewpoint to create a more dynamic quality in the work.

I was particularly drawn to the cubism of Juan Gris, especially those works produced during the years of World War I. I found the elegance and geometric rigor of these papiers colles and paintings compelling. I began to incorporate the ruled line and edge into my drawings and occasionally into the paintings to achieve the crisp, 
precise quality they provided. They offered a counterpoint to the freely drawn lines and I found the combination interesting and appealing.

A friend offered to model about this time so I decided to tackle the figure again (Figure 9). No great pains were taken with arranging the pose. I did not want the model to look posed. I included the table and still life as an inanimate contrast to the figure. Ironically the final result recalls the Mannerist paintings of Bronzino where the inanimate objects seem more lively than the human subjects. This was the inevitable result of my taking great pains with the figure and treating the still life in a more casual manner.

While dealing with the figure still had its problems for me, I did at least move towards taking greater liberties with the composition and surface treatment in this painting. I used two different views of the model and added a mirror to increase the spatial ambiguity. I felt these alterations made the composition more challenging. I also changed the position of one of the woman's legs but I left the leg deliberately sketchy with a portion of the previous position of the leg still visible. This created a sense of movement that seemed to contradict the stillness of the rest of the figure. This contradiction is echoed in the still life where the right side is painted in illusionistic detail while the left side remains only 


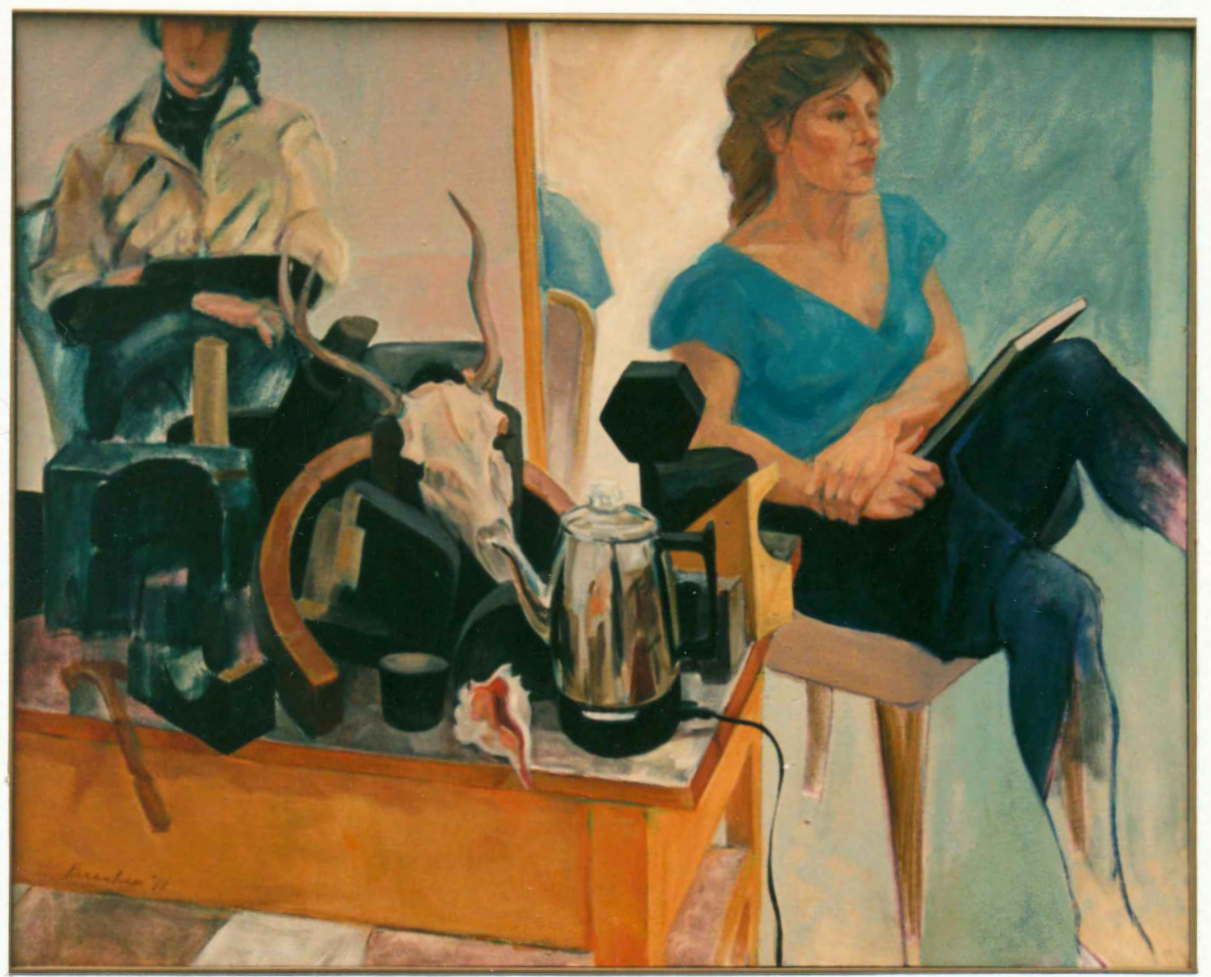

Figure 9. Cycle 
partially completed. The figure on the left, a repeat of the pose from a different viewpoint, is treated in a similarly sketchy manner to contrast with the highly rendered figure.

It was becoming clearer to me that I could do anything in a painting in terms of manipulating the composition and finish of the work. I was not tied to the logic of optical reality. Accepting this idea was an important step in trying to break free of a reliance on rendering. I was discovering that a process of working initially from observation and then continuing the work from memory and imagination allowed me to concentrate on the formal requirements of the painting. The strong influence of the observed object was mitigated and I was more willing to take liberties for the sake of what was occurring in the painting as it developed.

In the painting Two views (Figure 10) I wanted to combine the front and rear view of the table and still life in a different way -- to move beyond traditional perspective. The double overlapping image presented new compositional problems since I wanted both the illusion of volume and, at the same time, a sense of two dimensions. I tried to achieve this by treating the sides and legs of the table as flat rectangles of color without using the convention of making some of the legs appear farther back in space by altering hue value and intensity. Cropping the 


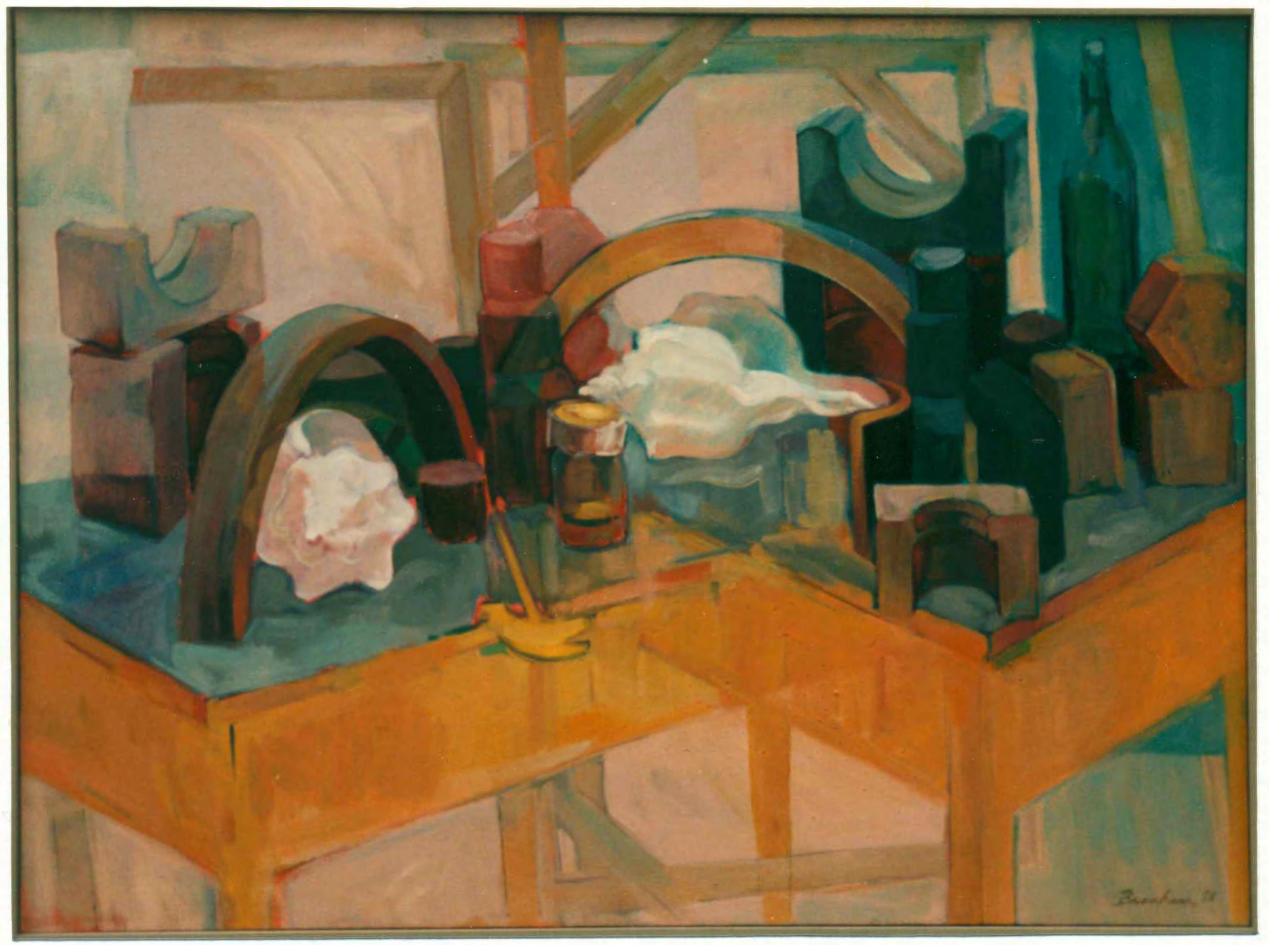

Figure 10. Two views 
table at the bottom of the picture plane added to the sense of flatness since generally it is the position of the bases of objects that provide spatial clues. The objects on top of the table are described in planes and are more volumetric but suggestions of transparency break up the forms into interlocking planes that suggest the devices of cubism. This greater removal from realism inspired me to move away from local color to a greater degree. While this painting was an important step in the direction I was trying to go, I felt that the treatment was still too representational. In a drawing I would change from tone to line to move from the illusion of dimension to an acknowledgement of the flat surface plane but I had yet to discover an analogous means in painting to accomplish the same end.

In Table and shadow (Figure ll) I tried to flatten the forms even more dramatically but, at the same time, I wanted to let the forms read spatially. I used color and references to western perspective to accomplish this. The table legs are shown in exaggerated perspective while the top is shown frontally and sharply tilted. I used strong rusty oranges and ochres on the table and the tilted floor plane and cool blue-green and dark grey in the upper right corner to make that area recede spatially. I also wanted to try to achieve more textural variation in this painting so I added a pattern of brush strokes on the floor plane to 


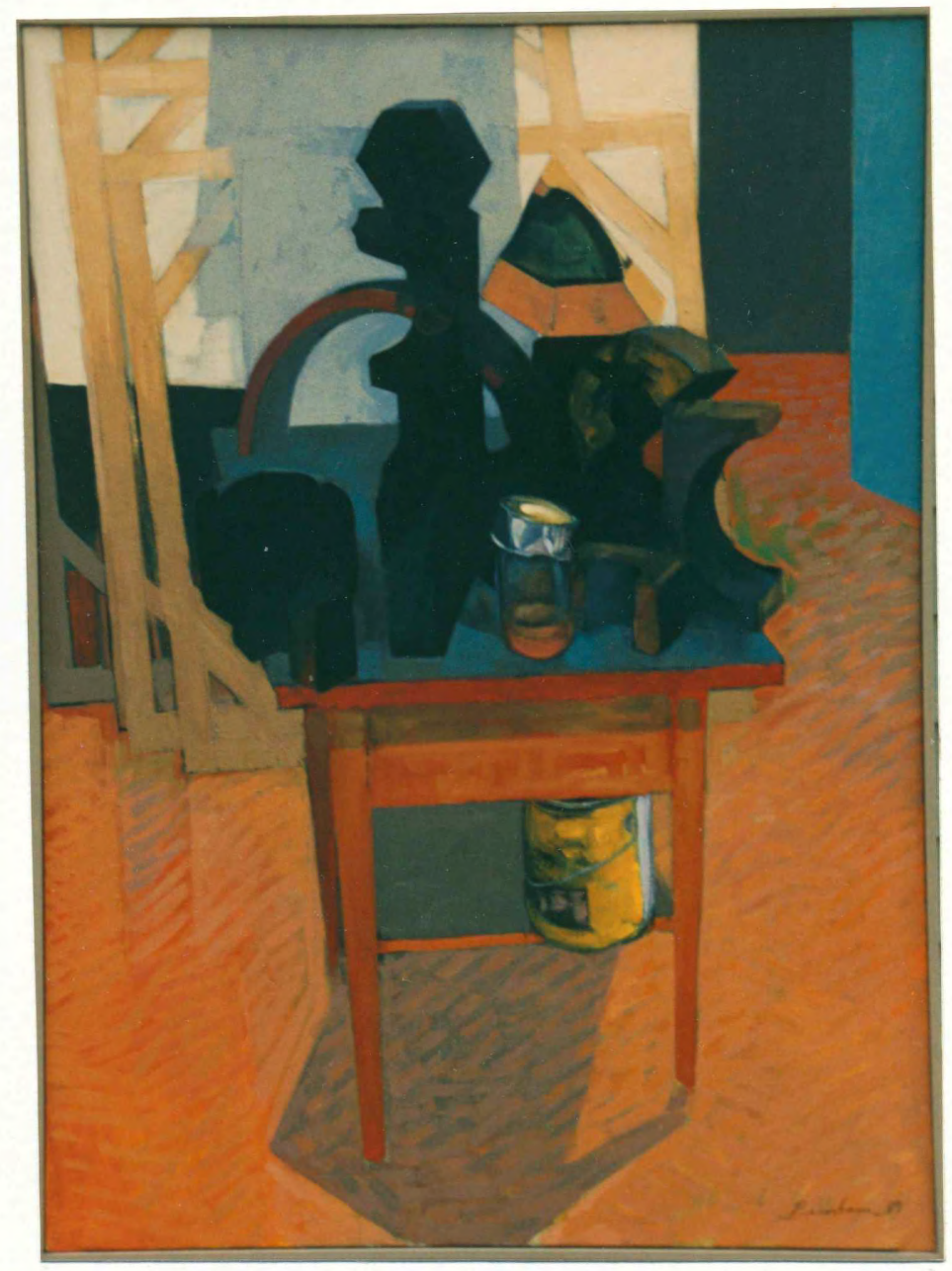

Figure 11. Table and shadow 
enliven that area. I felt that this painting was an important step towards clarifying the visual idea of the tension between surface and depth that I had been pursuing. Nevertheless, the tendency towards rendering stubbornly remained.

With Table and shadow another area of interest began to assert itself. The pattern molds had been drastically simplified to achieve strong units of black. It seemed to me that these forms now began to take on a formal, almost ceremonial quality in their stacked, massed combinations, that I found intriguing. The first drawings and paintings in this series had been primarily an exploration of formal issues but $I$ was becoming interested in the psychological role these forms played. The obvious fact that they were purposefully designed, but with a purpose that remained obscure, gave them a hermetic, enigmatic quality.

In The necromancer's studio (Figure 12) I tried to exploit this quality. To enhance the sense of mystery I placed the pattern molds and table in the near foreground. The bottom of the table is cut off by the edge of the canvas which creates an unsettling sense of the table springing up from an unseen space. I deliberately ignored the convention of acknowledging local color in order to enhance the sense of the surreal in the scene. For the same reason the background is left somewhat ambiguous. The figure was introduced because I felt that an organic shape 


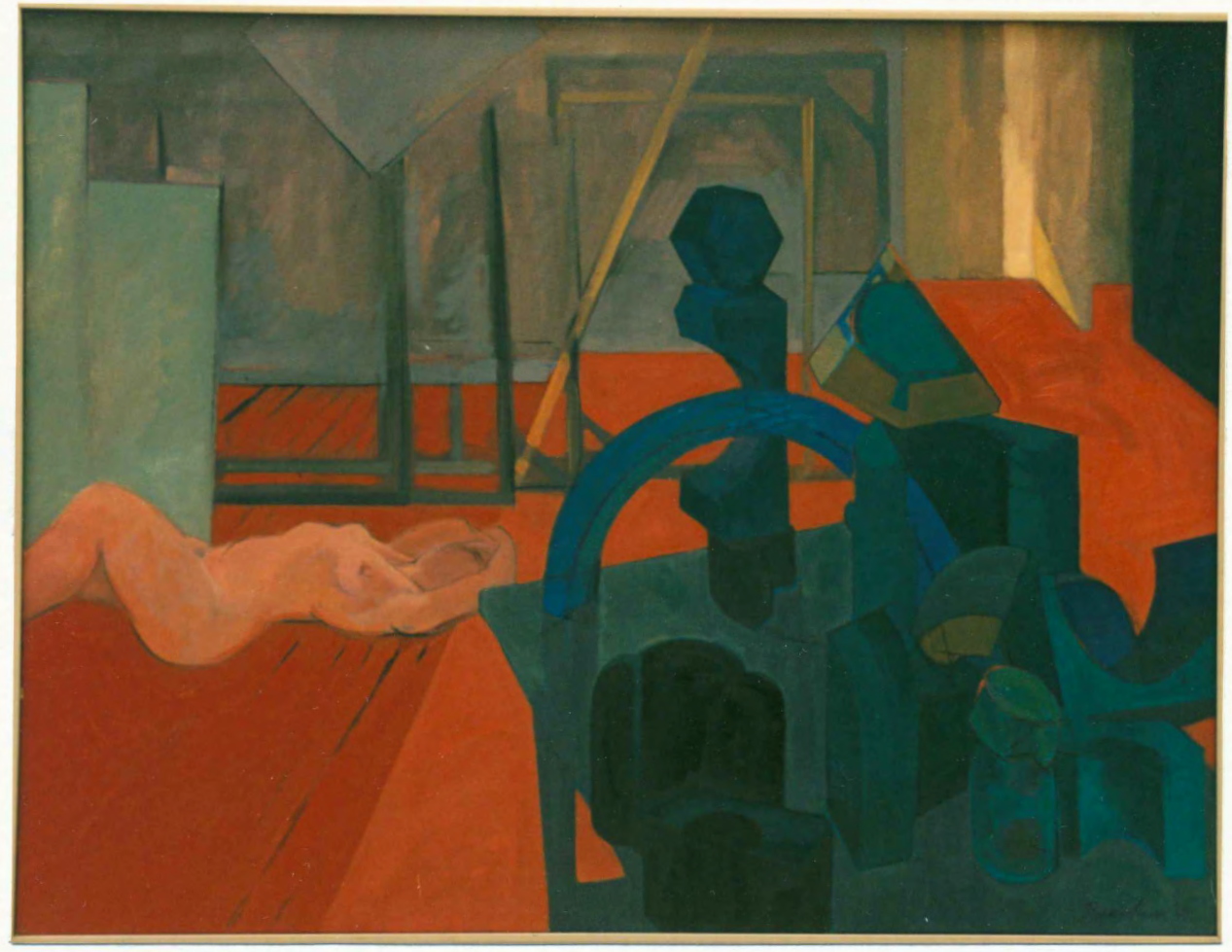

Figure 12. The necromancer's studio 
was needed as a counterpoint to the geometric shapes. The figure introduces expectations and resonances that a psychologically neutral object could not.

During the period I was working on the paintings. I was also working on a series of drawings as a means of exploring visual ideas that later would be developed more fully in paintings. It was in the drawings that I first began to explore some of the cubist ideas of multiple views of objects and their methods of defining space while at the same time acknowledging the two dimensions of the picture plane. Triptych (Figure 13), a pastel and charcoal drawing, was the first time that I experimented with the drastically tilted ground plane and extreme simplification of the objects that I would later use in painting. This drawing was a major step in finding solutions for the problems I had been trying to resolve but it still was not an easy matter to translate these ideas into painting.

The nature of the drawing process exposes the artist's thought processes in the numerous adjustments to the image that remain visible in the completed work. Byron Gardner suggested that I try to develop this same sense of process and spontaneity in my paintings. He also suggested that I look at Richard Diebenkorn's work for ideas on a means of combining my interest in geometric structure and a richer, freer surface treatment. Diebenkorn's approach places great importance on improvisation, an idea I used in my 


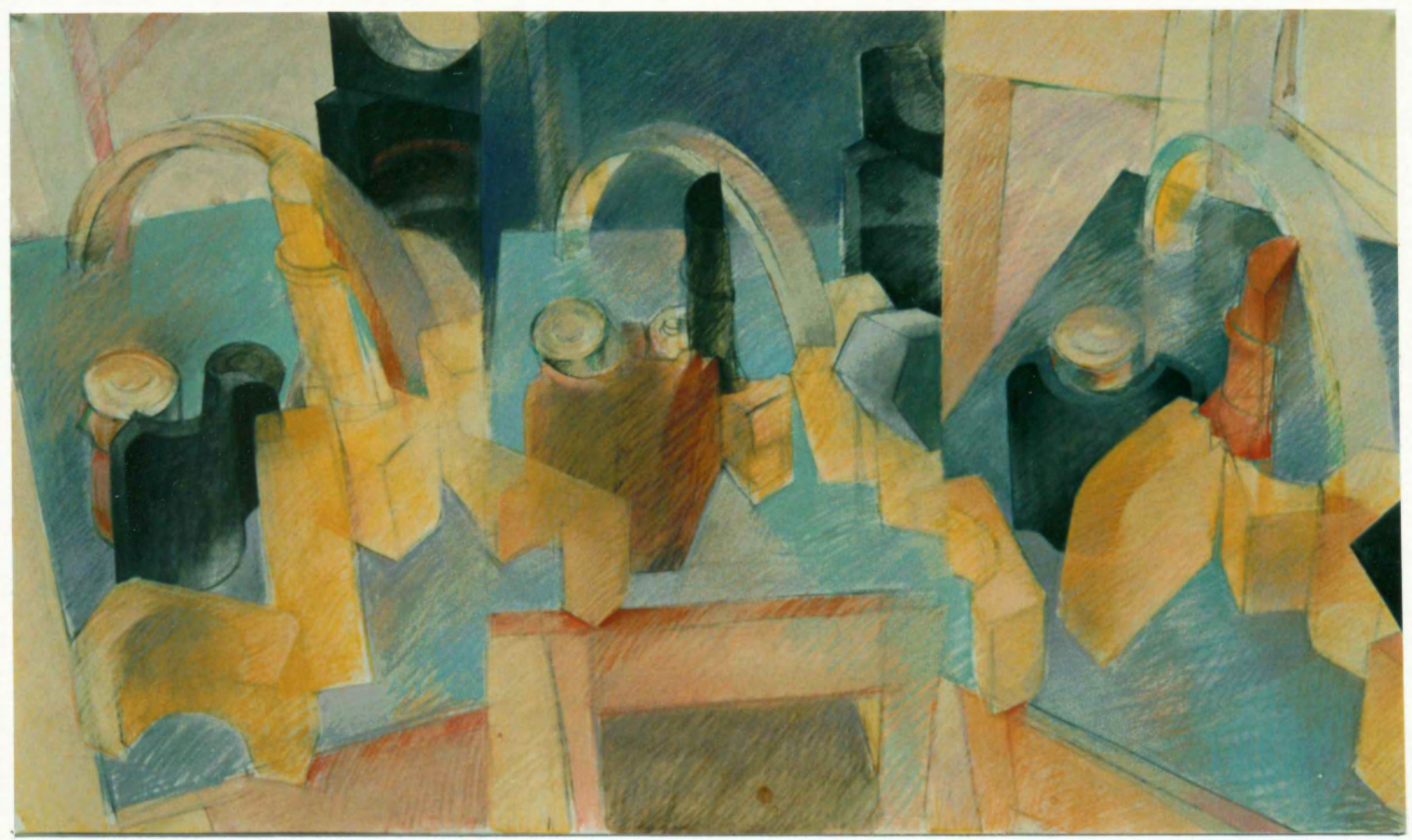

Figure 13. Triptych 
drawings but was having difficulty incorporating into my paintings. His work stresses the intuitive approach "...with its trials and errors, and its signs of the journey to completion..." (Ashton 1985) I was particulary interested in the concepts of "structural rigor" and "painterly release" demonstrated in his work (Hunter 1985, p. 389). They suggested the next step in the series of visual ideas that I had been pursuing.

I wanted to integrate negative space and positive forms more fully in the large canvas, Tables and skull (Figure 14). I was attempting to create a more subtle set of cues in suggesting the boundaries between objects and space. I dissolved the edges of objects in parts of the painting allowing the remaining edges, color and textural clues to complete the image of the table. An intriguing and unexpected result of this approach was that the forms on the table seem to float in midair. I increased the color and value contrast between the still life objects and the table to emphasize this effect. Again I tried to vary the brush strokes, to emphasize the painting surface. In some areas the paint is applied vigorously to convey a sense of energy within the confines of the geometric boundaries. In other areas the paint is applied thinly, sometimes in glazes, to contrast with the more densely painted areas.

The blue table (Figure 15) was the most daring step 


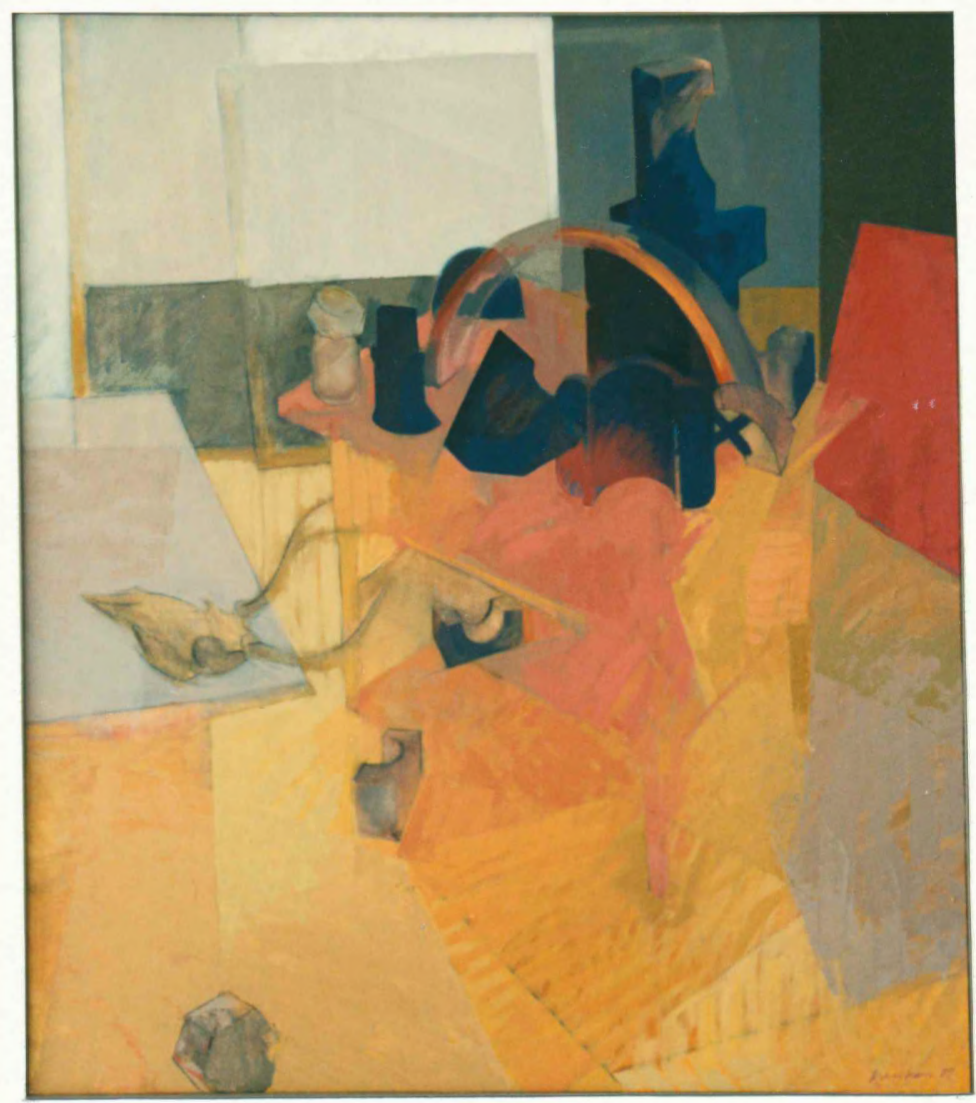

Figure 14. Tables and skull 


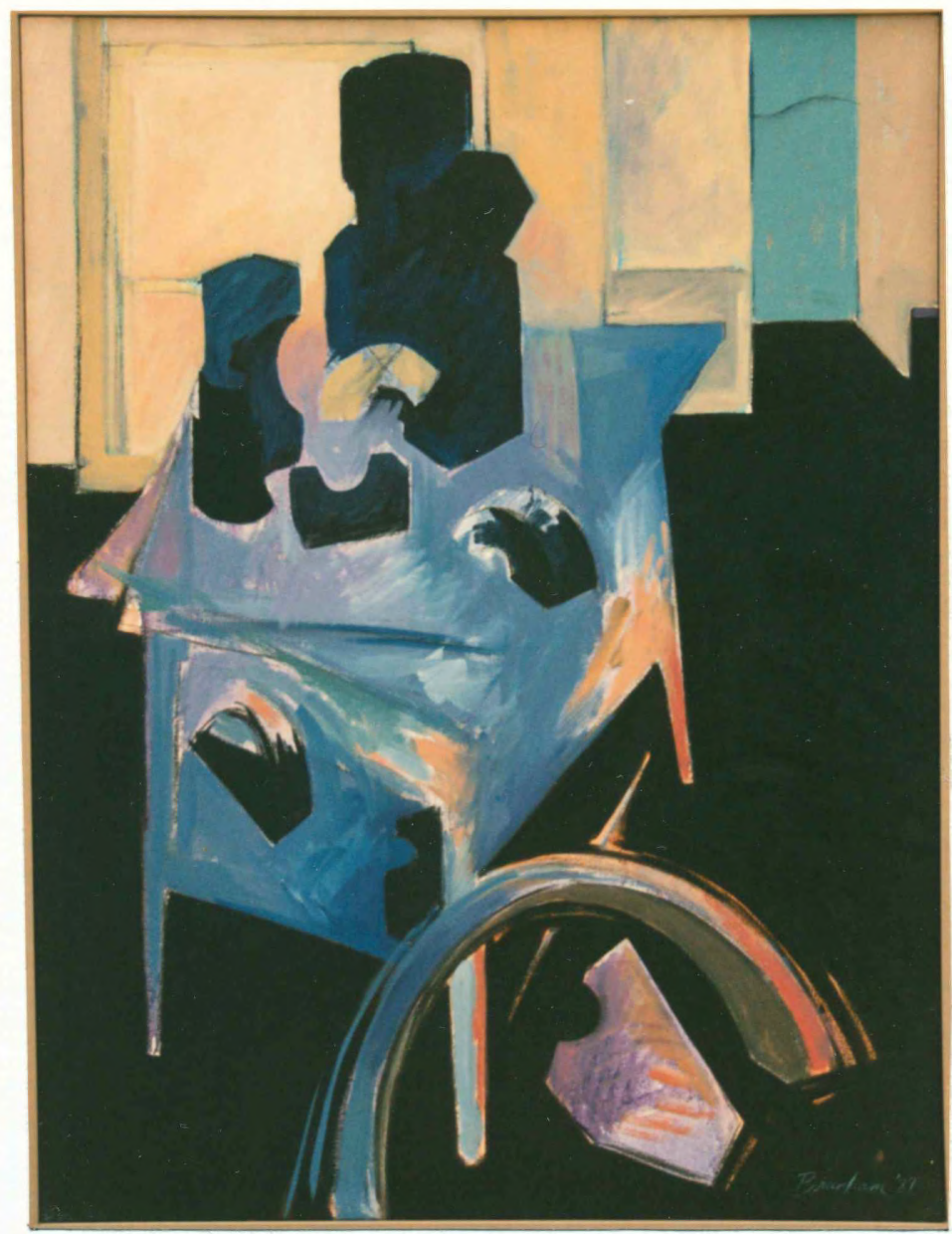

Figure 15. The blue table 
towards locking together figure and ground in strong, flat patterns. I decided to paint the floor black in order to completely reverse local color and value. I suspected that such a dramatic reversal would suggest a new approach for the rest of the painting and it certainly did! Because the table shape was so strongly defined by the black negative space I felt comfortable with dispensing with any description of the interior details of the table and still life objects. The shape of the table was composed of edges derived from several shifts in viewpoint. I felt this created a more dynamic image and, in response to this, the colors on the table were applied in a free, expressionistic manner. While the identity of figure and ground is still strong, the separation of form and space has been minimized. I had long admired Matisse's work for its simplicity in stating form and for its lyrical use of color. In painting the blue table I felt that I was finally beginning to understand what he was trying to do. At last I had broken free of merely rendering subject matter and had found a way of making a statement that was fresh and, at the same time, true to the subject matter. Working step by step through a series of drawings and paintings of the same subject matter proved to be the means of finding my own vision. Van Gogh wrote of the value of the sequential series: 
I draw repeatedly till there is one drawing that is different from the rest, which does not look like an ordinary study, but more typical and with more feeling. (Hirschl 1986, p.277)

While I had not initially planned to stay with the same subject matter throughout the year, the familiarity gained through repetition proved liberating.

In this series I had, to a large degree, moved away from the concept of chance arrangements as stated in the thesis proposal since, of necessity, the objects had to be placed on the table in an arrangement that suited my purposes as I began to clarify the ideas I was pursuing. objects behind the table were usually whatever happened to be hanging or leaning on the back wall of the studio. Nevertheless, by this time I was relying on chance occurrences in the painting process to move the work forward. I deliberately did a minimum of planning when I began a painting, having only a vague idea of what I wanted to see. I wanted to leave the door open wide for the operation of intuition. 


\section{CONCLUSIONS}

Over this two year period I have moved from wanting the painting to be very "complete" in terms of attention to finish and observed detail, to doing painting that allows process to remain visible in the final version. I have moved from making subject matter my primary concern to an emphasis on the visual issues of painting such as form, color and the tension between the painting surface and spatial illusion.

I now understand more clearly the strengths and limitations of my own artistic vision -- my artistic personality, so to speak. Looking back at work done prior to coming to Portland State, work going back many years, I can see those same interests expressed in many ways. I feel that what I have accomplished in my time in graduate school is to focus on those essential ideas and pare away the extraneous material. This process is by no means complete. As the work moved along, interesting detours and side trips suggested themselves and no doubt in the future there will be backtracking to earlier stages to re-examine an idea from a different perspective. Whatever direction my work takes in the future, my desire is to produce work 
that has integrity and is based on an informed response to images and ideas that catch my interest.

"Exactitude is not truth."

Henri Matisse (Hirschl 1986, p. 226) 


\section{REFERENCES CITED}

Ashton, Dore. "The Finesse of Richard Diebenkorn," Small Paintings from ocean Park, Houston, 1985 .

Hirschl, Milton. Creative Figure Drawing. New Jersey, 1986.

Hunter, Sam and John Jacobus. Modern Art, second edition. New York, 1985.

Tsujimoto, Karen. Wayne Thiebaud. San Francisco, 1985. 